\title{
CARACTERIZAÇÃO ELETROQUÍMICA DE NITINOL ANODIZADO ${ }^{1}$
}

\author{
Alana Rocha Schmidt Witt ${ }^{2}$ \\ Luciane Thaís Führ ${ }^{3}$ \\ Leonardo Marasca Antonini ${ }^{4}$ \\ Simone Vendruscolo Milesi $i^{5}$ \\ Denis Villarinho ${ }^{3}$ \\ Célia de Fraga Malfatti ${ }^{6}$
}

\section{Resumo}

O Nitinol tem sido muito estudado para utilização em implantes biomédicos devido as suas propriedades de memória de forma e superelasticidade. Contudo, há uma preocupação quanto à liberação de níquel no organismo. Nesse contexto, tratamentos de superfícies tem sido propostos. O processo de anodização, por exemplo, permite a formação de um óxido na superfície, o qual pode funcionar como uma barreira física impedindo a migração do níquel para o tecido adjacente. Muitos dos processos de anodização propostos na literatura empregam eletrólitos contento fluoretos, o que é prejudicial do ponto de vista operacional e ambiental. O trabalho tem por objetivo realizar a caracterização eletroquímica do Nitinol anodizado com solução ácida isenta de fluoreto. Após a anodização, as amostras foram avaliadas quanto ao comportamento eletroquímico por OCP e Voltametria Cíclica, conforme norma ASTM F2129-08. As amostras foram caracterizadas quanto à molhabilidade por monitoramento do ângulo de contato, e a composição química superficial foi avaliada por Espectroscopia Raman e Difração de Raios-X. As amostras foram avaliadas também por microscopia eletrônica de varredura. Os resultados obtidos mostraram-se coerentes com estudos já publicados para amostras anodizadas com eletrólitos contendo fluoretos. As amostras anodizadas apresentaram um aumento da resistência à corrosão comparativamente ao Nitinol sem tratamento eletroquímico.

Palavras-chave: Nitinol, Anodização, Caracterização Eletroquímica, Implantes biomédicos.

\begin{abstract}
Nitinol alloy is extensively studied for biomedical implants due to its shape memory and superelasticity properties. However, the release of nickel in the body it is a problem. A possible solution to avoid the nickel migration is the anodization, that is a process used to obtain an oxide layer which act as a barrier. Many anodizing processes proposed in the literature employ electrolytes containing fluorides, which present a health and environment problems. In this context, the aim of this study is to obtain and characterize anodized Nitinol surfaces using fluoride-free acidic electrolyte. After the anodization process, the samples were evaluated by OCP monitoring and cyclic voltammetry measurements, as ASTM F2129-08, to evaluate the electrochemical behavior. Furthermore, the wettability of the samples was characterized by the contact angle measurements. And the surface chemical composition was analyzed by Raman and X-ray diffraction. The surface morphology of the samples was evaluated by scanning electron microscopy. The obtained results was in agreement with studies presented on the literature for anodized samples with electrolytes containing fluoride. The anodized samples showed a corrosion resistance increased compared to electrochemical untreated Nitinol.

Key words: Nitinol, Anodization, Electrochemical Characterization, Biomedical implants.

1 Contribuição técnica ao $68^{\circ}$ Congresso Anual da ABM - Internacional, 30 de julho a 2 de agosto de 2013, Belo Horizonte, MG, Brasil.

2 Biomédica. Mestranda. Departamento de Engenharia, Laboratório de Pesquisa em Corrosão (Lapec), Universidade Federal do Rio Grande do Sul (UFRGS), Porto Alegre, RS, Brasil.

3 Engenheiro Mecânico. Msc. Doutorando. Depto. de Engenharia, Lapec, UFRGS, Porto Alegre, RS, Brasil.

4 Químico Industrial. Msc. Doutorando. Depto. de Engenharia, Lapec, UFRGS, Porto Alegre, RS, Brasil.

5 Graduanda em Engenharia Metalúrgica, Depto. de Engenharia, Lapec, UFRGS, Porto Alegre, RS, Brasil.

6 Engenheira Metalúrgica. Dr. Coordenadora. Depto. de Engenharia, Lapec, UFRGS, Porto Alegre, RS, Brasil.
\end{abstract}

ELECTROCHEMICAL CARACTERIZATION OF ANODIZED NITINOL 


\section{INTRODUÇÃO}

Desde o seu descobrimento, em 1962, o Nitinol vem sendo amplamente estudado devido as suas propriedades de memória de forma e superelasticidade. As notáveis características deste material o tornam uma excelente alternativa para 0 desenvolvimento de implantes biomédicos. ${ }^{(1)}$ Contudo, há uma preocupação no que diz respeito à liberação de níquel no organismo, por este ser um elemento potencialmente alergênico, tóxico e carcinogênico. Uma possível solução seria a anodização destas peças para que o óxido formado funcione como uma barreira física impedindo a migração do níquel para o tecido adjacente. ${ }^{(2)}$ Muitos dos processos de anodização propostos na literatura empregam eletrólitos contendo fluoretos, o que é prejudicial do ponto de vista operacional e ambiental. Nesse contexto $^{(3,4)}$ o trabalho tem por objetivo realizar a caracterização eletroquímica do Nitinol anodizado com solução ácida isenta de fluoreto.

\section{MATERIAIS E MÉTODOS}

\subsection{Preparação das Amostras}

Para este estudo foram avaliadas amostras de Nitinol polidas mecanicamente, (denominadas Polida), e amostras polidas mecanicamente e posteriormente anodizada uma área de $0,64 \mathrm{~cm}^{2}$, (denominadas Anodizada), com eletrólito isento de fluoreto, a $25^{\circ} \mathrm{C}$, com tensão de $60 \mathrm{~V}$ durante 10 minutos, sob agitação. A formulação não será mencionada nesse trabalho, pois o processo está sendo patenteado.

\subsection{Caracterização das Amostras}

\subsubsection{Molhabilidade}

O teste de molhabilidade foi realizado pelo método da gota séssil a partir de um aparato desenvolvido pelo Laboratório de Pesquisa em Corrosão (LAPEC) da Universidade Federal do Rio Grande do Sul (UFRGS) que determina o ângulo de contato formado através da interação entre a gota de solução tampão fosfato salino (PBS), e solução Simulated Body Fluid (SBF) ${ }^{(5)}$ e o substrato analisado. O ângulo de contato foi determinado por meio de um programa de análise de imagens.

\subsubsection{Morfologia: Microscopia de força atômica (AFM)}

As imagens foram obtidas com o microscópio de força atômica SPM-9500J3 SHIMADZU operando em modo de contato, com scanner com variação vertical de 8 $\mu \mathrm{m}$ e área de varredura de $125 \mu \mathrm{m} \times 125 \mu \mathrm{m}$. A partir dessas imagens geradas por AFM em 2D, realizou-se a determinação do diâmetro das nanoestruturas formadas. Estas medidas foram obtidas através do software Image J, através da média de vários pontos superficiais medidos para cada amostra.

\subsubsection{Composição química: espectroscopia Raman}

Para os ensaios de Espectroscopia Raman, utilizou-se espectrômetro Renishawin Via Spectrometer System for Raman Spectral Analysis, com laser de $514 \mathrm{~nm}$. A aquisição e tratamento dos dados foi realizada com o software Wire. 


\subsubsection{Composição química e estrutural: difração de raios-X (DRX)}

Para as análises de DRX foi utilizado difratômetro operando a 40 kV e 20 mA, em ângulo rasante de $5^{\circ} \mathrm{com}$ ânodo de cobre.

\subsubsection{Comportamento eletroquímico}

Os ensaios de OCP (open circuit potential) e voltametria foram realizados conforme a norma para determinação de suscetibilidade à corrosão de implantes médicos pequenos ASTM F2129-08. ${ }^{(6)}$

\subsubsection{Solução fisiológica utilizada para a caracterização eletroquímica}

A solução fisiológica utilizada para realização dos testes de caracterização eletroquímica foi SBF (simulated body fluid) conforme Kokubo e Takadama descreveram em 2006. ${ }^{(5)}$

2.2.6 Morfologia e composição química: microscopia eletrônica de varredura (MEV) e detector de energia dispersiva (EDS)

A caracterização morfológica das amostras após os testes eletroquímicos por MEV foi realizada em um microscópio modelo JSM 5800 - marca JEOL aplicando $20 \mathrm{KV}$. A análise EDS foi realizada utilizando sistema de dispersão em energia com capacidade de detecção de elementos entre B e U.

\section{RESULTADOS}

\subsection{Molhabilidade}

A anodização diminuiu o ângulo de contato gerado com as soluções PBS e SBF. Na Tabela 1 são demonstrados os valores dos ângulos encontrados.

Tabela 1. Média dos ângulos de contato das amostras Polida e Anodizada com solução PBS e SBF

\begin{tabular}{c|c|c}
\hline Amostra & Ângulo de contato em PBS & Ângulo de contato em SBF \\
\hline Polida & $79^{\circ} \pm 7^{\circ}$ & $74^{\circ} \pm 6^{\circ}$ \\
\hline Anodizada & $42^{\circ} \pm 11^{\circ}$ & $24^{\circ} \pm 2^{\circ}$ \\
\hline
\end{tabular}

\subsection{Morfologia: Microscopia de Força Atômica (AFM)}

Na Figura 1 são apresentadas as imagens em 3D obtidas por AFM, que mostram a topografia de cada uma das amostras. Já na Tabela 2 são apresentadas as rugosidades nanométricas calculadas através de 3 áreas por amostra.

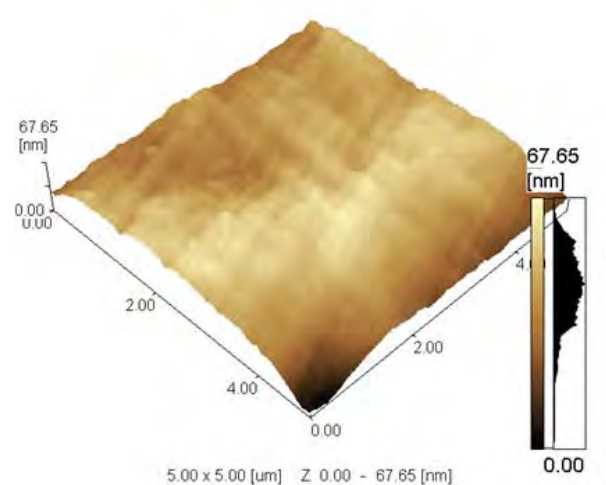

(a)

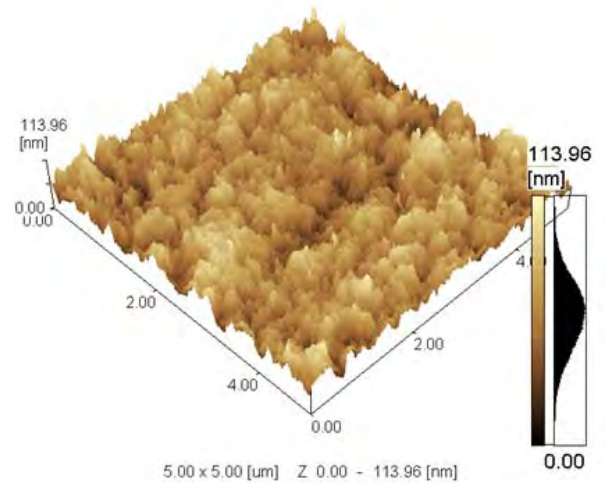

$500 \times 500[u m] z 000-113.96[\mathrm{~nm}]$

Figura 1. AFM 3D da amostra Polida (a) e Anodizada (b). 
Tabela 2. Medidas de rugosidade por AFM

\begin{tabular}{cccc} 
& \multicolumn{3}{c}{ Rugosidade } \\
\cline { 2 - 4 } Amostra & $\mathrm{Ra}(\mathrm{nm})$ & $\mathrm{Rms}(\mathrm{nm})$ & $\mathrm{Rz}(\mathrm{nm})$ \\
\hline Polida & $7,3 \pm 0,6$ & $9102 \pm 0,8$ & $35,0 \pm 4,1$ \\
Anodizada & $211,7 \pm 14$ & $5214,6 \pm 1,7$ & $856,3 \pm 4,5$ \\
\hline
\end{tabular}

\subsection{Composição Química: Espectroscopia Raman}

O espectro de Raman (Figura 2) Erro! Fonte de referência não encontrada. sugere que o óxido formado pela anodização é semelhante ao óxido naturalmente formado espontaneamente no NiTi.

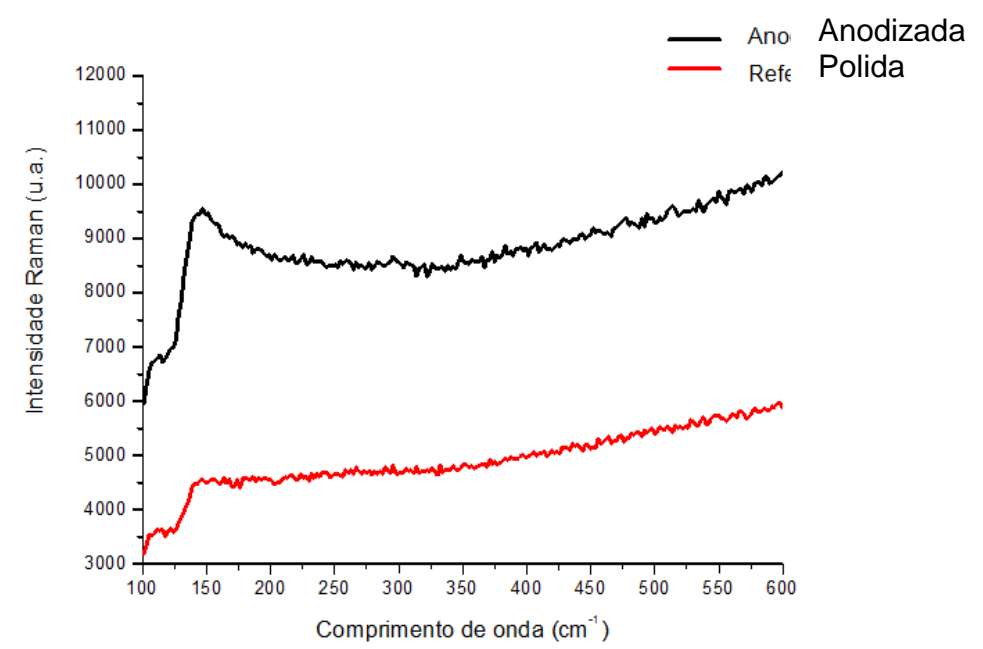

Figura 2. Espectro Raman da amostra Anodizada e Polida.

\subsection{Composição Química e Estrutural: Difração de Raios-X (DRX)}

A Figura 3 apresenta os difratogramas de DRX para a amostra Polida e para a amostra Anodizada.

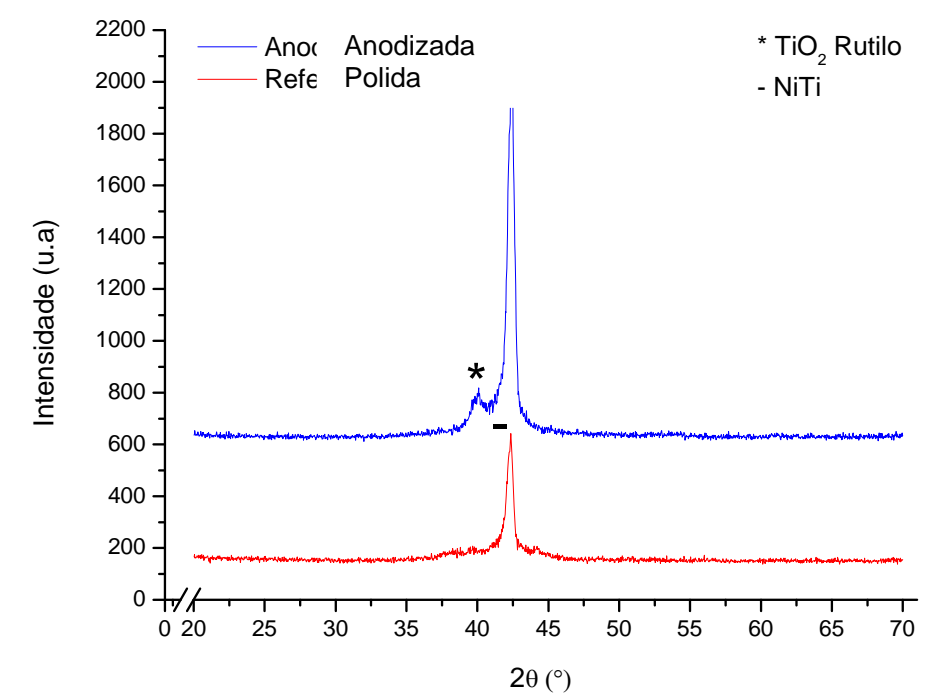

Figura 3. Resultado gráfico de DRX da amostra de Nitinol Polida em comparação com a amostra Anodizada. 


\subsection{Comportamento Eletroquímico}

\subsubsection{Pontencial de circuito aberto (OCP)}

A medida de OCP foi monitorada durante 1 hora em cada amostra, e o valor encontrado utilizando-se eletrodo de calomelano, -0,13 $\mathrm{V}$ para a amostra Polida e $0,10 \mathrm{~V}$ para a amostra Anodizada, foi utilizado como base para o ensaio de voltametria cíclica.

\subsubsection{Voltametria cíclica}

A Figura 4 apresenta as curvas resultantes do ensaio de voltametria cíclica para as amostras Polida e Anodizada.

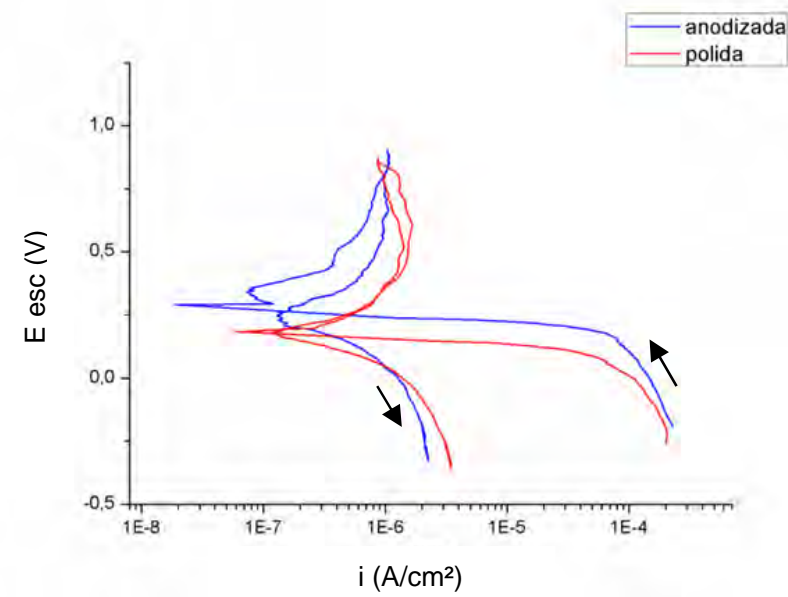

Figura 4. Curva de voltametria cíclica em meio SBF para das amostras Polida e Anodizada

\subsection{MEV e EDS}

As imagens geradas por MEV demonstraram corrosão pontual das amostras Polida e Anodizada Figura 5.

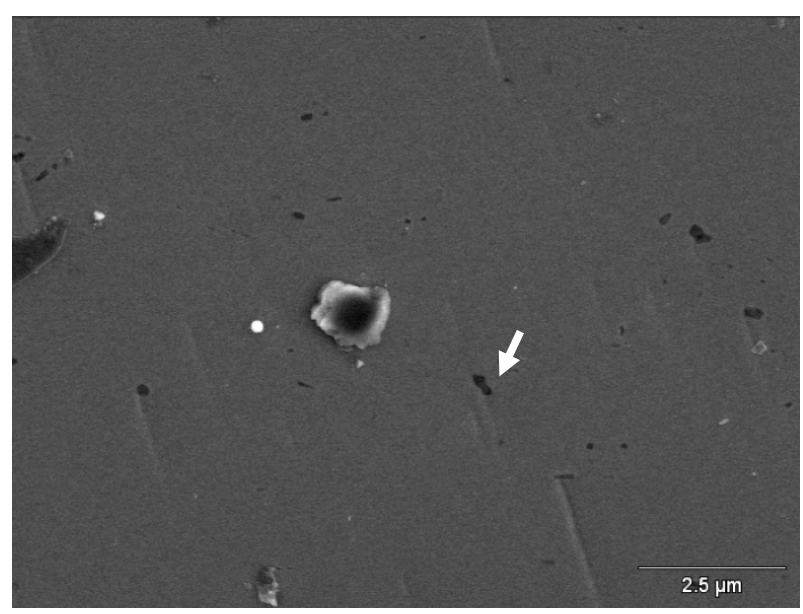

(a)

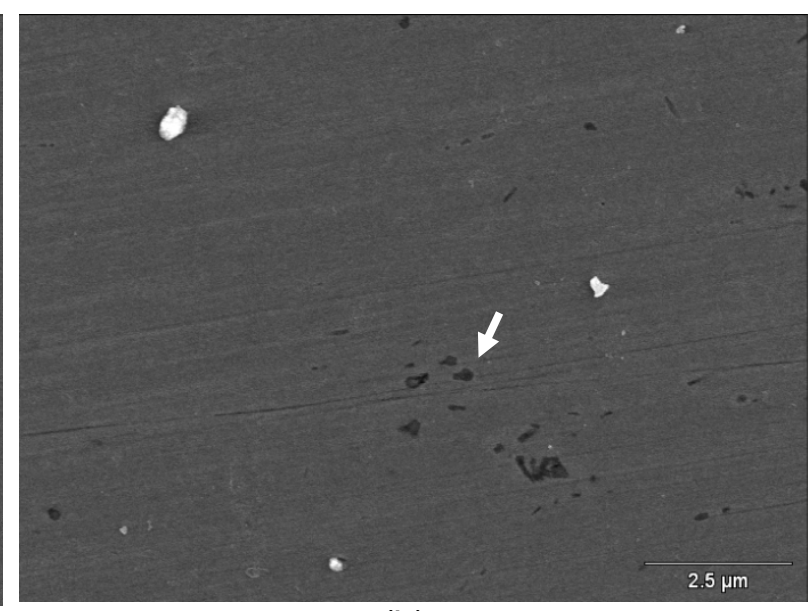

(b)

Figura 5. Imagem gerada por MEV após caracterização eletroquímica da amostra de Nitinol Polida (a) e Anodizada (b).

As análises por EDS indicam uma maior concentração de níquel na superfície da amostra que foi apenas polida (Figura 6) em relação àquela que foi também anodizada previamente (Figura 7) a caracterização eletroquímica. 
$68^{\text {th }}$ abm international annual congress
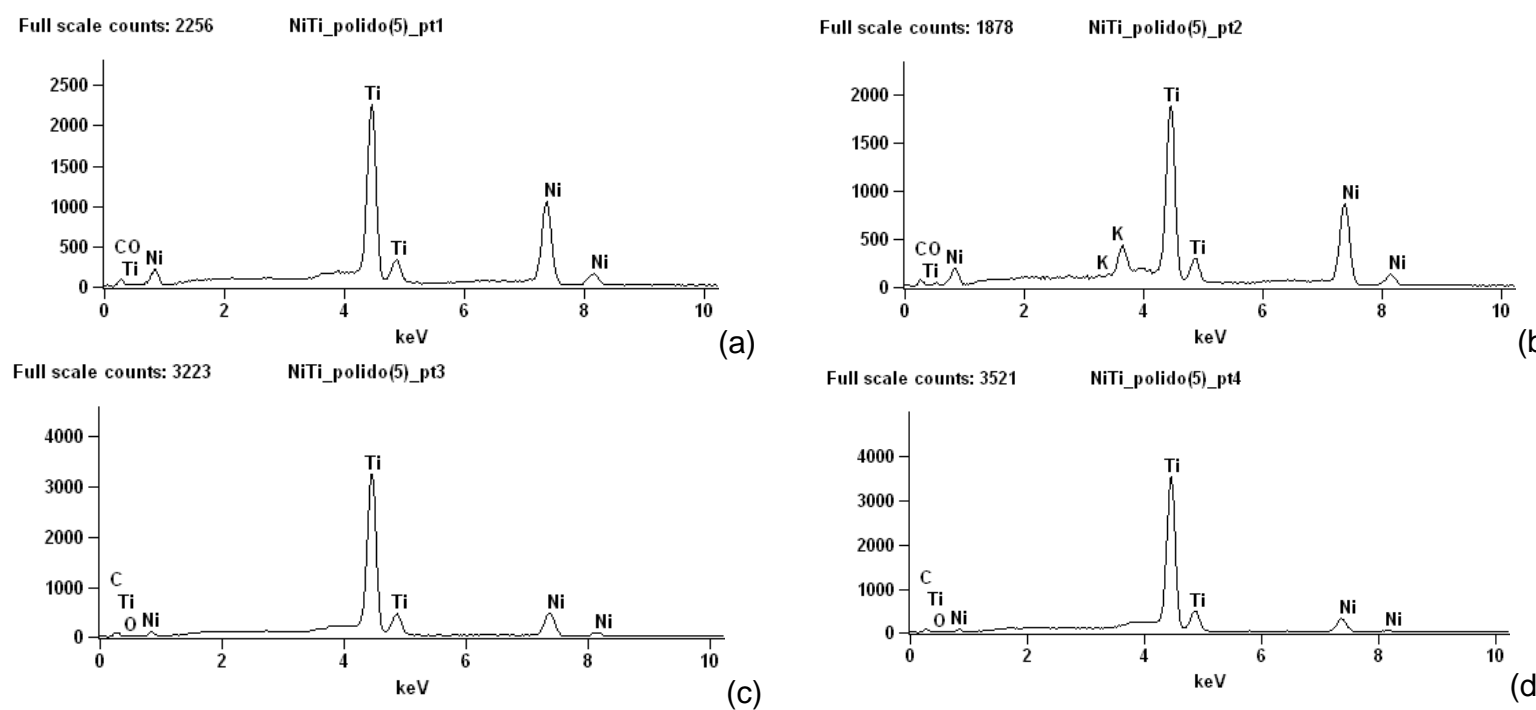

(a)

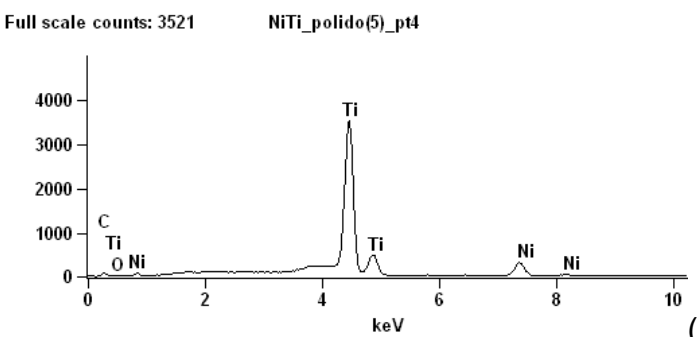

(c)

Full scale counts: $2824 \quad$ NiTi_polido(5)_pt5

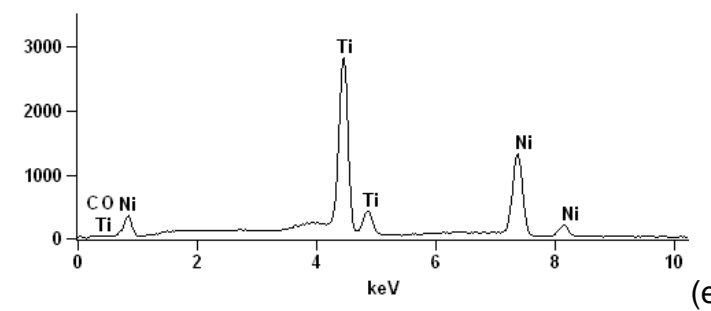

(e)

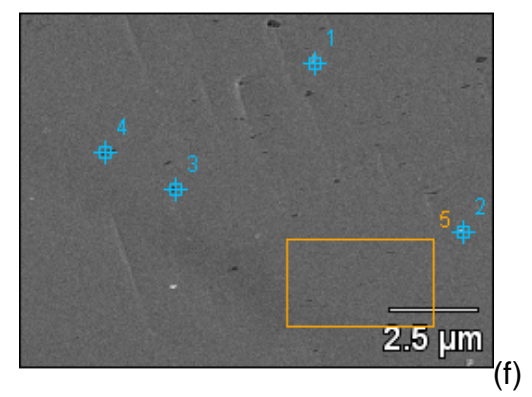

(d)

Figura 6. Análise por EDS da amostra de Nitinol Polida (a) Análise do ponto 1, (b) análise do ponto 2 , (c) análise do ponto 3, (d) análise do ponto 4, (e) análise da área 4, (f) localização dos pontos e da área analisada.
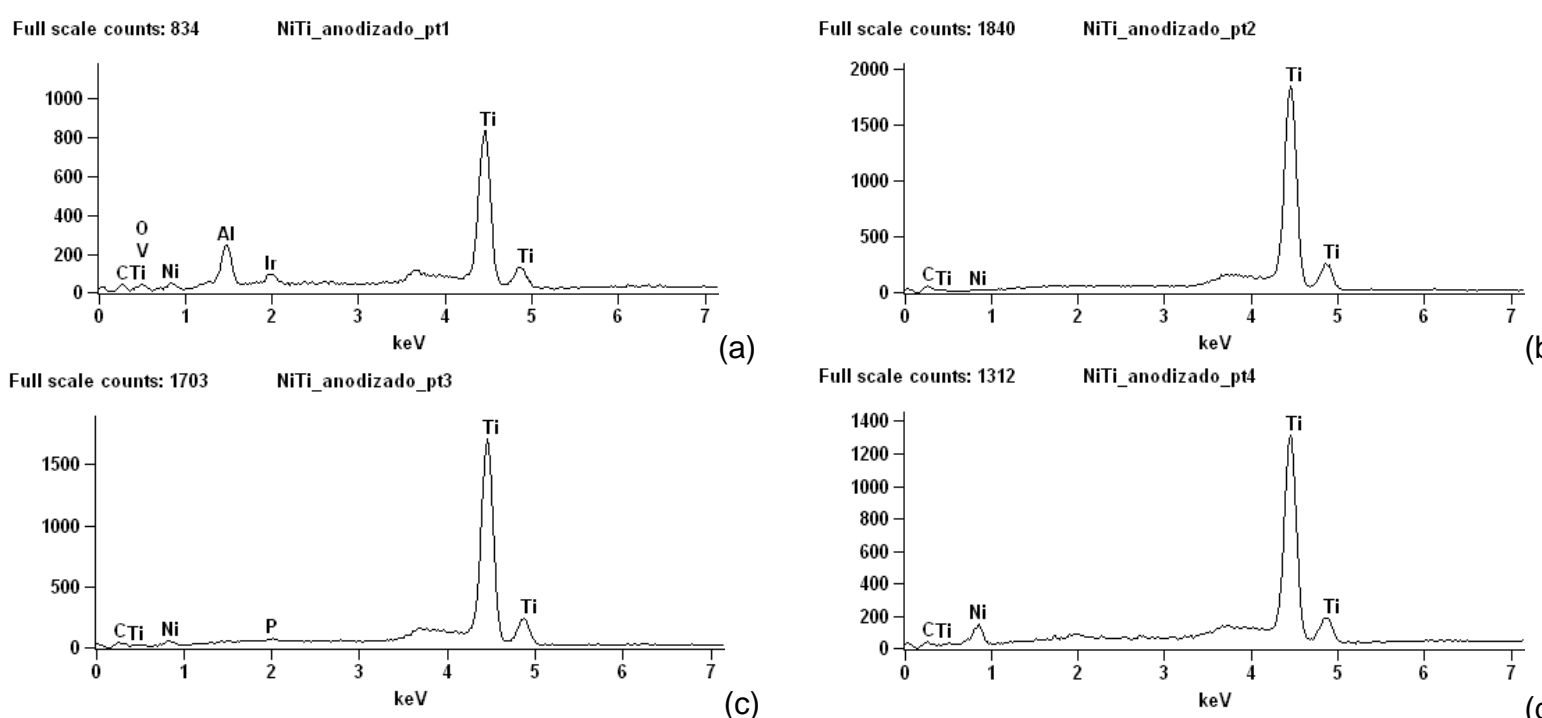

Full scale counts: 1312 NiTi_anodizado_pt4
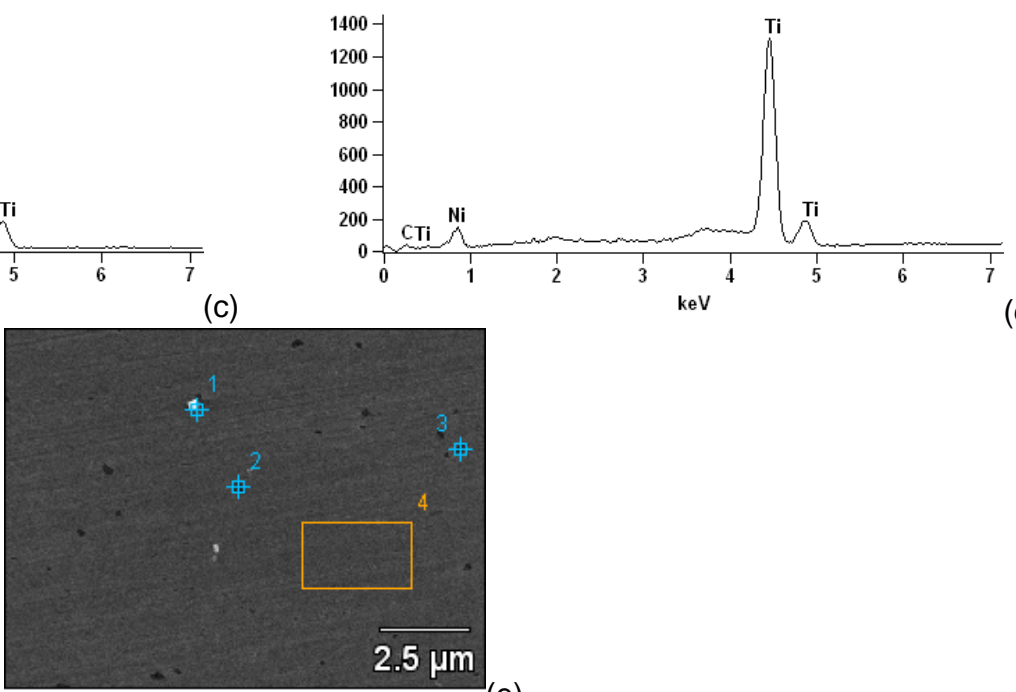

(d)

(e)

Figura 7. Análise por EDS da amostra de Nitinol anodizado. (a) Análise do ponto 1, (b) análise do ponto 2 , (c) análise do ponto 3, (d) análise da área 4, (e) localização dos pontos e da área analisada. 


\section{DISCUSSÃO}

As propriedades da superfície de um implante representam um importante papel na determinação da biocompatibilidade e na sua integração com o organismo, devido ao seu contato direto com as células sanguíneas e do tecido hospedeiro. Consequentemente a camada externa da anodização do material é de extrema importância na determinação da interação do material do implante com o corpo e do corpo com 0 material. ${ }^{(7)}$ Características da superfície, incluindo topografia, composição química, e energia de superfície são críticas para a atividade de osteoblastos em biomateriais. Tais características contribuem especialmente para a primeira fase de interação célula-material; a adesão e o espalhamento influenciam a capacidade da célula de proliferar e se diferenciar em contato com o implante. ${ }^{(4)}$ A modificação da superfície é um método fácil e barato de melhorar as características da superfície e aprimorar a biocompatibilidade de biomateriais, sem que se percam as propriedades do material base. ${ }^{(8)}$

Conforme demonstrado na Tabela 1, a amostra Polida apresenta ângulo de contato próximo ao limiar entre a hidrofilicidade e hidrofobicidade, demonstrando que a superfície do Nitinol sem tratamento eletroquímico parece não ser adequada ao crescimento celular, visto que o meio celular é aquoso. ${ }^{(7,9)}$ A adesão, o espalhamento, e a proliferação celular são fortemente afetados pela molhabilidade da superfície dos biomateriais. Um balanço entre hidrofobicidade e hidrofilicidade da superfície tem sido considerado o mais adequado para a adesão e proliferação celular. ${ }^{(9)}$ Já a amostra Anodizada teve uma diminuição significativa, em torno de 40\% (Tabela 1), no ângulo de contato, como esperado.Conforme já foi demonstrado em outros artigos, a anodização do Nitinol aumenta a molhabilidade de sua superfície, devido ao aparecimento de uma micro/nano textura. ${ }^{(7,8)}$ Outro fator importante seria atribuído à formação de uma camada de óxido como resultado da anodização, considerando que as camadas de óxido cerâmico, particularmente $\mathrm{TiO}_{2}$, formados na superfície do Nitinol tem um caráter iônico bastante elevado, e por isso exibe uma maior molhabilidade que os filmes de óxido passivo das superfícies não anodizadas. Esse conjunto de características apresentadas pela amostra Anodizada (Tabelas 1 e 2), favorece a adesão e proliferação celular sobre esta superfície. Bernard et al. ${ }^{(7)}$ mostraram resultados experimentais que também demonstram que a anodização do Nitinol transforma a superfície lisa da amostra Polida em uma micro/nanotextura.

A interação entre células e implantes é influenciada por processos físicos e químicos, sendo que o fator mais importante é a rugosidade da superfície. A topografia pode influenciar as células de várias formas, restringindo o acesso dos canais de difusão aos nutrientes, e a saída de seus resíduos. ${ }^{(10)}$ Devido à ampla gama de variáveis que influenciam as interações entre as células e a estrutura de superfície, é difícil apontar conclusões e formular princípios gerais para nano e microestruturas de superfície. ${ }^{(8)}$ As interações entre células e nanorugosidades são de maior interesse, pois essas superfícies parecem ser mais eficientes na promoção das funções celulares do que as topografias em escala micro. ${ }^{(4)}$ Portanto, a nanotexturização produzida pela anodização da amostra de Nitinol, conforme verificado nas Figuras 1 e 2, favoreceria a ancoragem celular devido ao aumento da rugosidade.

Quanto ao comportamento eletroquímico é possível observar uma diminuição da densidade de corrente na região anódica para a amostra Anodizada comparativamente à amostra Polida (Figura 4). Contudo é possível visualizar 
corrosão localizada tanto na amostra Polida como na amostra Anodizada, indicado pelas setas brancas na Figura 5. Tratamentos mencionados na literatura melhoram à resistência à corrosão reduzindo a densidade de corrente de corrosão e aumentando a região passiva e deslocando os potenciais de corrosão para valores mais positivos. ${ }^{(11)}$ No entanto, Chrzanowski et al. ${ }^{(12)}$ concluíram que o ensaio de resistência à corrosão da liga de Nitinol em fluído corporal simulado não é capaz de gerar um resultado satisfatório, e por isso deve ser associado à ensaios de estresse e fadiga. Porém outro estudo mostra uma diferença pouco significativa nos ensaios de corrosão por fadiga, em relação aos ensaios convencionais por polarização cíclica. ${ }^{(13)}$

Já está bem estabelecido que a superfície do Nitinol é principalmente composta por óxido de titânio estável $\left(\mathrm{TiO}_{2}\right)$, uma pequena parcela de óxidos de níquel (NiO e $\left.\mathrm{Ni}_{2} \mathrm{O}_{3}\right)$ e $\mathrm{Ni}$ metálico. ${ }^{(10,11)}$ Apenas a amostra Anodizada apresentou pico característico do óxido de titânio estável Rutilo e/ouAnatásio (Figura 3). Estudos já publicados por outros autores mencionam esses óxidos para superfícies de nitinol anodizadas. ${ }^{(7,14-16)}$ A análise de DRX apresentou, em ambas amostras, um pico característico de NiTi característico do substrato, ${ }^{(7,10,17-21)}$ evidenciando que o filme de óxido formado provavelmente, apresenta baixa espessura. Já foi demonstrado que a concentração de Ni na superfície pode variar consideravelmente dependendo do tratamento de superfície aplicado, o que está de acordo com os resultados encontrados neste estudo, onde o EDS da amostra Anodizada (Figura 7) apresentou uma menor concentração de níquel, em relação à amostra Polida (Figura 6). A biocompatibilidade do Nitinol tem sido atribuída à estabilidade mecânica e termodinâmica das camadas de óxido estáveis que se formam na sua superfície. ${ }^{(10)}$ As superfícies modificadas podem prevenir efetivamente a liberação do níquel se a integridade da superfície for mantida em stress e se subcamadas ricas em níquel não estiverem presentes. ${ }^{(11)}$

\section{CONCLUSÃO}

A anodização do Nitinol em eletrólito isento de fluoreto mostrou ser efetiva na diminuição da concentração de níquel na superfície e aumento da resistência à corrosão. Contudo, observou-se a presença de corrosão localizada na amostra Anodizada após os ensaios eletroquímicos, o que indica que estudos para o aperfeiçoamento da proteção contra a corrosão do Nitinol em fluído corpóreo simulado ainda são necessários.

\section{Agradecimentos}

O presente trabalho foi realizado com o apoio da Capes, entidade do Governo Brasileiro voltada para a formação de recursos humanos. Os autores agradecem também o apoio financeiro do CNPq e da Fapergs.

\section{REFERÊNCIAS}

1 SHABALOVSKAYA, S. A. et al. The electrochemical characteristics of native Nitinol surfaces. Biomaterials 30, pp. 3663-3671, 2009.

$2 \mathrm{KWOK}, \mathrm{D}$. T. K. et al. Surface treataments of nearly equiatomic NiTi alooy (Nitinol) for surgical implants. Biomedicals Engineering, Trends in Materials Science, InTech, 2011, pp. 269-282 .

3 SHABALOVSKAYA, S. A. et al. The influence of surfaces oxides on the distribuition and release of nickel from Nitinol wires. Biomaterials, pp. 468-477, Novembro 2009. 
$4 \mathrm{KIM}$, S-E. et al. Nanoporous anodic oxidation titanium enhances cell proliferation and differentiation of immortalized mouse embryonic cells. Surface and Coating Technology, 25 Setembro 2012.

5 KOKUBO, T.; TAKADAMA, H. How useful is SBF in predicting in vivo bone bioactivity? Biomaterials 27, pp. 2907-2915, 2006.

6 ASTM INTERNATIONAL, ASTM F2129-08 Standart test method for conducting cyclic potentiodynamic polarization measuraments to determine the corrosion susceptibility of small implant devides, 2008.

7 BERNARD, A. S. et al. Bone cell-materials interactions and Ni release of anodized equiatomic NiTi alloy. Acta Biomaterialia, pp. 1902-1912, 11 Janeiro 2011.

8 SHEN, Y. et al. Investigation of surface endotheliazation on biomedical nitinol (NiTi) alloy: Effects of surface micropatterning combined with plasma nanocoatings. Acta Biomaterialia, vol. 5, no. 9, pp. 3593-3604, Novembro 2009.

9 TANG, C. J. et al. A study on surface endotheliazation of plasma coated intravascular stents. Surface \& Coatings Technology, vol. 204, pp. 1487-1492, 2010.

10 PONSONNET, L. et al. Effect of surface topography and chemistry on adhesion, orientation and growth of fibroblasts on nickel-titanium substrates. Materials Science and Engineering C, vol. 21, pp. 157-165, 2002.

11 MILOSEV, I.; KAPUN, B. The corrosion resistance of Nitinol alloy in simulated physiological solutions Part 2: The effect of surface treatment. Materials Science and Engineering C, vol. 32, pp. 1068-1077, 2012.

12 CHRZANOWSKI, W.; WALKE, W.; ARMITAGE, D. K. J. Study on bioactivity of nitinol after surface treatment. Archives of Materials Science and Engineering 31, pp. 5-8, 2008.

13 DENTON, M.; EARTHMAN, J. C. Corrosion evaluation of wear tested nitinol wire. Materials Science and Engineering C, vol. 25, pp. 276-281, 2005.

$14 \mathrm{VOJTECH}$, D. et al. Surface structure and corrosion resistance of short-time heat-treated NiTi shape memory alloy. Applied Surface Science, vol. 257, pp. 1573-1582, 2010.

$15 \mathrm{VOJTECH}$, D. et al. Surface treatment of NiTi shape memory alloy and its influence on corrosion behavior. Surface Coatings and Technology, vol. 204, pp. 3895-3901, 2010.

$16 \mathrm{GU}$, Y.; TAY, B.; YONG, E. M. Characterization of bioactive surface oxidation layer on NiTi alloy. Applied Surface Science, vol. 252, pp. 2038-2049, 2005.

17 ASM, Metals Handbook. V. 2. Properties and Selection: Nonferrous Alloys and SpecialPurpose Materials, Novelty: ASM International, 1992.

$18 \mathrm{HORIUCHI}$, Y. et al. Effect of surface modification on the photocatalysis of Ni-Ti alloy in orthodontics. Dental Materials Journal, vol. 26, no. 6, pp. 924-929, 2007.

19 ELAHINIA, M. H. et al. Manufacturing and processing of NiTi implants: A review. Progress in Materials Science, vol. 57, no. 5, pp. 911-946, 2012.

20 BAYAT, N.; SANJABI, S.; BARBER, Z. H. Improvement of corrosion resistance of NiTi sputtered thin films by anodization. Applied Surface Science, vol. 257, pp. 8493-8499, 2011.

21 VOJTECH, D.; JOSKA, L.; LEITNER, J. Influence of a controlled oxidation at moderate temperatures on the surface chemistry of nitinol wire. Applied Surface Science, vol. 254, pp. 5664-5669, 2008.

22 ANTONINI, L. M. Superfícies nanoestruturadas de titânio e tratamento superficial com filmes Diamond Like Carbon (DLC). Porto Alegre, 2012.

23 RUIQIANG, H. et al. Preparation, characterization, corrosion behavior and bioactivity of Ni2O3 - doped TiO2 nanotubes on NiTi alloy. Electrochimica Acta, vol. 70, pp. 382-393, 2012.

24 DHAGE, S. R. et al. Synthesis of nanocrystalline TiO2 at 1001C. Materials Letters, vol. 58, pp. 2310-2313, 2004.

$25 \mathrm{VOJTECH}$, D. et al. Cyclic and isothermal oxidations of nitinol wire at moderate temperatures. Intermetallics, vol. 16, pp. 424-431, 2008.

26 FIRSTOV, G. S. et al. Surface oxidation of NiTi shape memory alloy. Biomaterials, vol. 23, pp. 4863-4871, 2002. 